\title{
DUKUNGAN PEMBERIAN ASI EKSKLUSIF PADA IBU BEKERJA
}

\author{
Farida Nur Khayati ${ }^{1}$, Zuly Daima Ulfa $^{2}$ \\ ${ }^{1,2}$ Akademi Kebidanan Duta Dharma Pati \\ E-mail:farida.abuprasti@gmail.com
}

\begin{abstract}
ABSTRAK
Cakupan pemberian ASI Eksklusif di Indonesia pada tahun 2017 sebesar 35,73\%, Provinsi Jawa Tengah mencapai 41,89\%. Cakupan ASI Kabupaten Pati tahun 2016 sebesar 74,2\% dan cakupan terendah pada tahun 2017 di Puskesmas Margorejo yaitu 35.8\%. Pencapaian cakupan ASI Eksklusif mengalami permasalahan diantaranya masih banyaknya perusahaan yang kurang memberi kesempatan pemberian ASI Eksklusif bagi pekerja wanita yang memiliki bayi umur 0-6 bulan .Tujuan penelitian adalah menganalisis dukungan pemberian ASI Eksklusif pada ibu bekerja.Metode penelitian kualitatif dengan desain retrospektif.Pengumpulan data secara in-depth interview.Informan dipilih dengan teknik purposive sejumlah 5 ibu bekerja yang memberikan ASI Eksklusif dan informan triangulasi sebanyak 2 orang. Hasil penelitian menujukkan bahwa pemberian ASI oleh ibu bekerja dengan cara ASI Perah (ASIP) dan menyusui langsung (jam istirahat dan sepulang kerja). Dukungan diperoleh dari suami, keluarga, tenaga kesehatan dan tempat bekerja dalam bentuk dukungan emosional, informasional, dan instrumental.
\end{abstract}

Kata Kunci: ASI Eksklusif; Dukungan; Ibu Bekerja

\section{EXCLUSIVE BREASTFEEDING SUPPORT FOR WORKING MOTHERS}

\begin{abstract}
The coverage of exclusive breastfeeding in Indonesia in 2017 was $35.73 \%$, in Central Java Province reached 41.89\% (Ministry of Health of the Republic of Indonesia 2018). The coverage of exclusive breastfeeding at Pati District in 2016 was 74.2\% (Pati District Health Office 2017) and the lowest coverage in 2017 at Margorejo was 35.8\% (Margorejo Public Health Community 2018). The achievement of exclusive breastfeeding coverage has experienced problems including the number of companies that lack the opportunity to provide exclusive breastfeeding for female workers who have infants aged 0-6 months (Central Java Provincial Health Office 2016). The aim of the study was to analyze the support of exclusive breastfeeding for working mothers. Qualitative research method used with retrospective design. Data collection used in-depth interviews. The informants were selected by purposive technique with 5 working mothers who were exclusive breastfeeding. Analysis comprises content analysis of data. Support of husband, family, midwifes and workplaces is given in emotional, informational, and instrumental.
\end{abstract}

Keywords: Support;Exclusive Breastfeeding; Working Mother 


\section{Pendahuluan}

Kematian balita pada tahun 2015 sebanyak 5,9 juta jiwa atau sekitar 16.000 setiap hari. Kematian balita sebesar 83\% disebabkan oleh infeksi, kondisi bayi baru lahir dan masalah nutrisi. WHO merekomendasikan inisiasi dini menyusui dalam 1 jam setelah kelahiran dan ASI Eksklusif untuk 6 bulan pertama kehidupan, namun fakta menunjukkan hanya 43\% saja bayi 0-6 bulan diberikan ASI secara eksklusif. Pemberian ASI secara optimal sangat penting karena dapat menyelamatkan lebih dari 800.000 nyawa anak balita setiap tahunnya (WHO 2016).

Cakupan pemberian ASI Eksklusif di Indonesia pada tahun 2015 sebesar 55.7\%, mengalami peningkatan dari periode sebelumnya dan telah mencapai target renstra tahun 2015 yaitu 39\%. Cakupan provinsi Jawa Tengah mencapai $56.1 \%$ dari bayi yang berjumlah 398.358 jiwa. Jawa tengah merupakan peringkat 6 terendah dari propinsi yang mencapai target renstra (Kementerian Kesehatan RI, 2016). Determinan pemberian ASI Eksklusif menurut Astuti (2013) adalah pendidikan, pekerjaan, pengetahuan, dan sikap ibu serta peran petugas, keterpaparan media, peran suami, peran orang tua. Ibu rumah tangga memiliki peluang 0.17 kali untuk memberikan ASI eksklusif pada ibu bekerja. Ibu yang kembali bekerja penuh sebelum bayi berusia 6 bulan menyebabkan pemberian ASI tidak berjalan semestinya ditambah kondisi fisik, mental dan diet yang kurang memadai.

Beberapa fenomena menunjukkan pengalaman menyusui secara eksklusif pada ibu bekerja adalah praktik menyusui secara eksklusif pada ibu bekerja dipengaruhi oleh persepsi dan pemahaman ibu yang diperoleh dari pengetahuan yang diperoleh dari tenaga kesehatan atau sumber informasi lain yang diperoleh secara langsung maupun tidak langsung. Budaya dan mitos yang berkembang di masyarakat ada yang bersifat mendukung menyusui secara eksklusif maupun sebaliknya (Rejeki, 2010).

\section{Tinjauan Teoritis}

ASI Eksklusif adalah memberikan ASI saja kepada bayi tanpa tambahan makanan atau minuman lainya termasuk air putih, sampai bayi umur 6 bulan (WHO 2016). Undang-undang RI nomor 13 tahun 2003 tentang ketenagakerjaan memuat pekerja/buruh perempuan berhak memperoleh istirahat selama 1,5 (satu setengah) bulan sebelum saat melahirkan anak dan 1,5 (satu setengah) bulan sesudah melahirkan menurut perhitungan dokter kandungan atau bidan. Undang-Undang RI Nomor 36 Tahun 2009 tentang kesehatan mengatur selama pemberian air susu ibu, pihak keluarga, pemerintah, pemerintah daerah, dan masyarakat harus 
mendukung ibu bayi secara penuh dengan penyediaan waktu dan fasilitas khusus. Ketentuan tentang dukungan program ASI eksklusif di tempat kerja telah diatur dalam PP Nomor 33 tahun 2012 tentang Pemberian ASI Eksklusif sesuai dengan kondisi kemampuan perusahaan.

Pemberian ASI Eksklusif pada ibu bekerja dipengaruhi beberapa faktor yaitu pekerjaan, peran petugas dan promosi susu formula (Oktora, 2013). Pemberian ASI Eksklusif pada ibu bekerja berhubungan dengan pengetahuan tentang ASI eksklusif dan motivasi ibu (Listyaningrum \& Vidayanti, 2016). Hasil tersebut berbeda dengan (Setyaningrum et al., 2017) bahwa tidak ada korelasi antara pengetahuan dan sikap ibu bekerja dengan pemberian ASI eksklusif, walaupun sikap baik tetapi kondisi pekerjaan tidak memungkinkan memberikan ASI eksklusif pada bayinya.

Analisis determinan perilaku pemberian ASI eksklusif pada ibu bekerja menunjukkan sikap merupakan variabel yang paling dominan, bersama variabel umur, ketersediaan fasilitas, dan dukungan pengasuh (Inayah \& Dian, 2012). Kondisi tersebut sejalan dengan penelitian (Anggraeni et al., 2016), bahwa perilaku pemberian ASI eksklusif sesuai dengan intensi ibu. Intensi kuat dapat mengatasi hambatan, terkait ketersediaan fasilitas, jarak tempat kerja dan jam kerja.

\section{Metode Penelitian}

Metode penelitian kualitatif dengan desain retrospektif. Model penelitian adalah fenomenologi, untuk memberikan gambaran tentang keberhasilan ibu-ibu bekerja dalam pemberian ASI Eksklusif. Penelitian dilaksanakan di Wilayah Kecamatan Margorejo Kabupaten Pati. Pengumpulan data dilakukan secara in-depth interview. Informan dipilih dengan teknik purposive sejumlah 5 ibu bekerja yang menyusui secara eksklusif dengan umur bayi 7-24 bulan. Pengolahan data terdiri content-analysis, mengambil kesimpulan dan verifikasi, narasi hasil analisis dalam bentuk pelaporan hasil penelitian dengan metode deskriptif. Penelitian ini dilakukan pada bulan Maret - Agustus 2018.

\section{Hasil Penelitian}

Dukungan dalam praktik pemberian ASI eksklusif pada ibu bekerja, diperoleh dari dukungan suami, keluarga, tenaga kesehatan dan tempat bekerja. Semua informan mendapat dukungan suami. Dukungan suami sebagian besar dalam bentuk dukungan emosional yaitu memberi semangat. Dukungan instrumental dalam bentuk pendampingan menyusui, 
mencucikan breast pump, mengisi ulang batre (charge) breast pump, menjadi kurir ASI dan finansial. Dukungan informasional misalnya tetap memberikan ASI meski ibu sakit, pemberian susu formula harus diimbangi dengan pemberian ASI. Dukungan keluarga berupa dukungan emosional (motivasi) dan dukungan informasional bahwa ASI lebih hemat, ASI lebih baik.

“... kalau saya kan pakai elektrik ya lebih praktis tinggal colok... pasti tiap malam lupa ngecas, lha itu yang ngecas suami... pas usia 2 mingggu adik kan opname karena bayi kuning, itu mau jadi kurir ASI ke RS trus secara finansial ya support...” (Informan 3, staf instansi)

“....ya pernah saya pas badannya gak enak, minta belikan susu formula tapi tidak boleh...” (Informan 1, Penjahit)

“... diperes ae nduk, duite dak ... nggo tuku opo-opo a...” (Informan triangulasi)

Dukungan tenaga kesehatan diperoleh ketika pemeriksaan kehamilan (ANC) mendapat informasi dari dokter atau Bidan, pendidikan kesehatan setelah persalinan dan kunjungan nifas. Pelaksanaan kelas ibu hamil sering tidak dapat diikuti oleh informan (ibu bekerja) karena pelaksanaan kegiatan pada saat jam kerja. Ada informan yang mendapatkan pemantauan pemberian ASI Eksklusif oleh Bidan. Informan yang tidak mendapat informasi dari tenaga kesehatan mengatakan keputusan menyusui dari keinginan sendiri. Sebagian informan tidak mengetahui informasi Pemberian ASI Eksklusif pada Ibu Bekerja. Informan mencari informasi secara aktif melalui internet.

“....info dari sosial media...” (Informan 4, Agen asuransi)

Dukungan instansi tempat bekerja berupa instansi atau karyawan terdapat peraturan tentang cuti hamil/bersalin/menyusui selama 1,5 sampai 3 bulan. Informan yang bekerja tanpa ketentuan jam kerja (penjahit, agen asuransi) melakukan manajemen waktu dengan menyesuaikan waktu bekerja dengan menyusui. Tempat bekerja berupa kantor kejaksaan mengijinkan memerah ASI pada jam kerja selaian itu juga menggunakan jam istirahat, yang dimanfaatkan untuk menyusui bayinya. Tempat bekerja berupa toko, instansi atau Rumah Sakit lebih fleksibel untuk pumping atau menyusui.

Tempat bekerja berupa toko menyediakan tempat untuk memerah ASI dan kulkas untuk menyimpan ASIP. Sedangkan tempat bekerja berupa Rumah Sakit terdapat ruang laktasi, kulkas dan poster ASI.

“..gak disediakan khusus sih, tapi kebetulan anaknya bosku juga ASI Eksklusif, kalau di toko ya malah freezer khusus ASI jadi saya nitip di freezer...” (Informan 2, karyawan swasta) 
“.. ruang laktasi ada, kulkas ada.. poster ada tidak ya, lupa.. tapi sekarang sudah pro ASI soalnya kalau lahirin pasti IMD langsung. "(Informan 5 dokter)

\section{Pembahasan}

Dukungan dalam praktik pemberian ASI eksklusif pada ibu bekerja dalam bentuk informasional, emosional maupun instrumental. Dukungan diperoleh dari dukungan suami, keluarga dan tenaga kesehatan. Dukungan tenaga kesehatan diperoleh ketika pemeriksaan kehamilan, setelah persalinan dan kunjungan nifas. Dukungan tempat bekerja berupa masa cuti, kelonggaran waktu untuk memerah ASI atau menyusui, serta penyediaan fasilitas (ruang untuk memerah ASI, kulkas) meskipun tidak disediakan secara khusus untuk menyimpan ASIP. Beberapa informan tidak menerima informasi ASI Eksklusif pada ibu bekerja namun mencari informasi sendiri dan menyusui atas keinginan sendiri. Hal tersebut tidak sesuai dengan (Oktora 2013) bahwa pemberian ASI Eksklusif pada ibu bekerja diantaranya dipengaruhi peran petugas.

Pabrik tempat bekerja telah menyediakan fasilitas sesuai PP Nomor 33 tahun 2012, berupa ruang laktasi dan sosialisasi pada ibu hamil, namun sosialisasi dan implementasi kurang efektif sehingga beberapa informan mengaku tidak tahu dan tidak pernah ke lokasi tersebut. Hal ini mendukung (Ismail et al. 2012) bahwa informasi harus lebih praktis dan terfokus, serta penyediaan fasilitas sangat dibutuhkan agar efektif dan aman. Teknologi yang relatif efektif dan aman misalnya cooler bag, harga terjangkau dan praktis.

Peraturan cuti selama 3 bulan, memerlukan strategi khusus agar mencapai ASI Eksklusif. Setelah masuk kerja, ibu tetap memerah ASI setiap 3 jam, menyimpan ASI kemudian membawanya pulang setelah selesai bekerja (Astuti 2013) namun tidak semua Pabrik dapat memberikan ijin setiap 3 jam karena mengganggu produksi. Beberapa informan dan keluarga merasa bayi tidak kenyang sehingga diberikan susu formula. Ibu pekerja membutuhkan dukungan serta kebijakan tentang ASI Eksklusif serta program edukasi yang mendorong pengetahuan ke dalam praktek (Dun-Dery \& Laar 2016), namun pada pelaksanaan terdapat kendala yaitu keterbatasan jumlah tenaga kesehatan di Pabrik.

Pemberian ASI Eksklusif pada ibu bekerja berhubungan dengan pengetahuan tentang ASI eksklusif dan motivasi ibu (Listyaningrum \& Vidayanti 2016). Hal ini sesuai hasil penelitian, bahwa ibu bekerja yang memiliki motivasi kuat (ASI makanan terbaik bayi, sehat dan hemat) dan didukung keluarga berhasil memberikan ASI Eksklusif bahkan ketika bayi umur lebih dari 6 bulan tetap mendapat ASI Perah disamping Makanan Pendamping ASI. 


\section{Kesimpulan}

Dukungan dalam pemberian ASI Eksklusif pada ibu bekerja diperoleh dari suami dan keluarga, tenaga kesehatan serta perusahaan atau tempat bekerja. Dukungan suami dan keluarga dalam bentuk dukungan emosional, informasional, dan instrumental. Dukungan tenaga kesehatan dalam bentuk informasional. Dukungan tempat bekerja berupa dukungan informasional dan instrumental. Kendala dalam pemberian ASI Eksklusif tidak ada. Fasilitas tempat bekerja berupa kelonggaran waktu, ruang laktasi dan kulkas.

\section{Saran}

Diperlukan dukungan serta motivasi dari suami dan keluarga dalam pemberian ASI Eksklusif pada ibu bekerja. Peningkatan sosialisasi Pemberian ASI Eksklusif pada ibu bekerja. Waktu pelaksanaan diatur sedemikian rupa sehingga ibu bekerja dapat mengikuti, menggunakan metode dan media efektif (media sosial, buku saku).

\section{Daftar Pustaka}

Anggraeni, et al. (2016). "Keberhasilan Ibu Bekerja Memberikan ASI Eksklusif.” Jurnal Gizi dan Dietetik Indonesia (Indonesian Journal of Nutrition and Dietetics) 3(2):69-76. from http://ejournal.almaata.ac.id/index.php/IJND/article/view/311.

Astuti, I. (2013). "Determinan Pemberian ASI Eksklusif Pada Ibu Menyusui." Health Quality $4: 1-76$.

Dinas Kesehatan Kabupaten Pati. (2017). Profil Kesehatan Kabupaten Pati Tahun 2016.

Dinas Kesehatan Provinsi Jawa Tengah. (2016). Profil Kesehatan Provinsi Jawa Tengah Tahun 2015. Semarang: Dinas Kesehatan Provinsi Jawa Tengah. from www.dinkesjatengprov.go.id.

Dun-Dery, E J., and Laar A. K. (2016). "Exclusive Breastfeeding among City-Dwelling Professional Working Mothers in Ghana." International Breastfeeding Journal 11(1):23. from http://internationalbreastfeedingjournal.biomedcentral.com/articles/

Ismail, et al. (2012). "Breast Milk Expression among Formally Employed Women in Urban and Rural Malaysia: A Qualitative Study." International Breastfeeding Journal 7(1):11.

Kementerian Kesehatan Republik Indonesia. (2012). "Peraturan Pemerintah Republik Indonesia No 33 Tahun 2012."

Kementerian Kesehatan Republik Indonesia. (2018). "Data dan Informasi Profil Kesehatan Indonesia 2017”. Jakarta : Kementrian Kesehatan RI

Listyaningrum, T. U., \& Vidayanti V. (2016). "Tingkat Pengetahuan dan Motivasi Ibu Berhubungan dengan Pemberian ASI Eksklusif Pada Ibu Bekerja." Jurnal Ners dan Kebidanan Indonesia 4(2):55. from http://ejournal.almaata.ac.id/index.php/JNKI/article/ 
Oktora, R. (2013). "Gambaran Pemberian ASI Eksklusif Pada Ibu Bekerja Di Desa Serua Indah, Jombang, Tangerang Selatan." Jurnal Kesehatan Masyarakat Nasional 4(1):3040 .

Puskesmas Margorejo. (2018). Laporan Cakupan ASI Eksklusif Puskesmas Margorejo.

Rejeki, S. (2010). "Studi Fenomenologi: Pengalaman Menyusui Eksklusif Ibu Bekerja Di Wilayah Kendal Jawa Tengah." Nurse Media Journal of Nursing 2(1):1-13. Retrieved (http://ejournal.undip.ac.id/index.php/medianers/article/view/734).

Undang-undang Republik Indonesia nomor 13 tahun 2003 tentang Ketenagakerjaan.

Undang-undang Republik Indonesia nomor 36 tahun 2009 tentang Kesehatan 